\title{
Double-blind controlled trial of amylopectin sulphate (Depepsen) in the symptomatic treatment of duodenal ulcer
}

\author{
J. H. BARON1, R. J. N. GRIBBLE, D. J. HOLDSTOCK, AND \\ J. J. MISIEWICZ
}

From St. Charles's Hospital, London, Ashford Hospital, Ashford, Middlesex, and the Medical Research Council Gastroenterology Unit, Central Middlesex Hospital, London

SUMmARY In a double-blind controlled trial amylopectin sulphate (Depepsen) had no significant advantage over placebo in the symptomatic treatment of duodenal ulcer.

Most treatments of duodenal ulcer have attempted to neutralise or diminish acid output or to increase mucosal resistance; little attention has been given to pepsin. Amylopectin sulphate (Depepsen, Searle) has been reported to be effective in both gastric and duodenalulcer (Cayer and Ruffin, 1967;Zimmon, et al., 1969; Sun and Ryan, 1970), though a negative study has also appeared (Cocking, 1972). We report here a double-blind trial of this agent in the asymptomatic treatment of duodenal ulcer.

\section{Methods}

Patients studied were men with radiological evidence of duodenal ulcer crater or deformity obtained within the previous two years. They had a history of six months to five years typical of duodenal ulcer, with pain on three or more days in the seven days before admission to the trial. There were no restrictions to entry into the trial because of age, cardiorespiratory or renal disease, but those with known gastric ulcer, hiatus hernia, gallstones, or irritable bowel syndrome, and those receiving anticholinergics, carbenoxolone, Caved-S, or gefarnate for their present relapse were excluded. Informed consent was obtained.

The patients were given their customary antacids and either amylopectin sulphate $500 \mathrm{mg}$ to be chewed and swallowed with a drink two hourly for six daily doses, or an identical appearing placebo tablet containing dextrose $500 \mathrm{mg}$ in place of the amylo-

\footnotetext{
${ }^{1}$ Address for correspondence: Dr. J. H. Baron, Department of Surgery, Royal Postgraduate Medical School, Hammersmith Hospital, London, W12 0HS.
}

Received for publication 2 February 1977 pectin. The patients were encouraged to take the amylopectin regularly and the antacid as often as required. They kept a diary card recording each day the presence or absence of daytime and nocturnal pain and the number of test tablets and antacids consumed. They were asked to grade the severity of the pain $0 / 1 / 2$. They were advised to stop smoking and, if dietary advice was requested, told to eat normal meals. Each patient was seen at fortnightly intervals for six weeks. At each visit the diary cards were collected and new ones issued. The results of treatment were analysed from data culled from the diary cards. Duodenoscopy, which is now mandatory for ulcer-healing studies, was not possible when this trial was started.

\section{Results}

The records were analysed by one observer, who had no clinical contact with any of the patients. Forty patients were entered into the trial, 21 receiving the placebo and 20 the active treatment. Eight patients (five in the placebo, three in the treatment group) defaulted from follow up, while the diary cards from four patients (all on active treatment) were incomplete and unsuitable for analysis. Diary cards were completed satisfactorily by 28 patients, 12 of whom received the active and 16 the placebo tablets. Data culled from the diary cards and by direct inquiry showed that all the patients appeared to take the tablets regularly and at the prescribed dose. The mean number of days and nights with ulcer pain per patient and the mean number of antacid tablets consumed per patient for each week of the trial period are shown in the Table. Depepsen had no advantage over the placebo when judged on 
Table Mean number of days and nights of ulcer pain and antacid tablets consumed during trial period

\begin{tabular}{|c|c|c|c|c|c|c|}
\hline \multirow[t]{2}{*}{ Week of trial } & \multicolumn{2}{|c|}{ Mean number of nights with pain/patient } & \multicolumn{2}{|c|}{ Mean number of days with pain/patient } & \multicolumn{2}{|c|}{ Mean number of antacid tablets/Patient } \\
\hline & Active & Placebo & Active & Placebo & Active & Placebo \\
\hline 1 & $3 \cdot 6$ & $2 \cdot 3$ & $5 \cdot 0$ & 3.8 & 18 & 14 \\
\hline 2 & $2 \cdot 7$ & $2 \cdot 3$ & $3 \cdot 1$ & $3 \cdot 7$ & 15 & 12 \\
\hline 3 & $2 \cdot 0$ & 1.8 & $3 \cdot 1$ & $3 \cdot 3$ & 12 & 10 \\
\hline 4 & $2 \cdot 0$ & 2.9 & $3 \cdot 3$ & 3.6 & 12 & 11 \\
\hline 5 & 1.5 & 1.7 & 2.9 & 2.6 & 13 & 9 \\
\hline 6 & $2 \cdot 1$ & $1 \cdot 3$ & $3 \cdot 1$ & 1.8 & 10 & 8 \\
\hline
\end{tabular}

either of these two criteria, nor was there any difference in the severity of pain. No side-effects were noted with either amylopectin or placebo tablets. The active and placebo groups were comparable in age, sex, and length of history.

\section{Discussion}

These observations show no advantage for amylopectin sulphate compared with placebo in the treatment of symptoms of duodenal ulceration. In both treatment groups daytime and nocturnal pain and antacid consumption decreased during the six weeks of the trial-the decrease presumably representing the spontaneous symptomatic remission in duodenal ulcer.

These results differ from the significant benefit with amylopectin sulphate $250 \mathrm{mg}$ two hourly reported by Sun and Ryan (1970) and Sun (1974). However, in a trial using amylopectin sulphate and propantheline, Cocking (1972) could show no advantage for amylopectin sulphate $500 \mathrm{mg}$ every three hours over a placebo, and in a recent endoscopically controlled eight week trial Landecker et al. (1976) also found no advantage for amylopectin.

Although amylopectin sulphate has been shown to inhibit gastric pepsin activity in man (Sun, 1967), it did not, in the dose range used in the present trial, produce significant relief of symptoms in patients with duodenal ulceration.

We wish to thank Searle and Co. Ltd., for supplying the active and placebo tablets.

\section{References}

Cayer, D., and Ruffin, J. M. (1967). Effect of depepsen in the treatment of peptic ulcer. Annals of New York Academy of Sciences, 140, 744-746.

Cocking, J. B. (1972). A trial of amylopectin sulphate (SN263) and propantheline bromide in the long term treatment of chronic duodenal ulcer. Gastroenterology, 62, 6-10.

Landecker, K., McCallum, E., Fevre, D. I., Green, P. H., Kasumi, A., and Piper, D. W. (1976). Effect of amylopectin (Depepsen) on the healing rate of chronic duodenal ulcer. (Abstract). Australian and New Zealand Journal of Medicine, 6, 256.

Sun, D. C. H. (1967). Effect of a synthetic sulfated polysaccharide (SN263) on gastric peptic activity in humans. Anrals of New York Academy of Sciences, 140, 747-753.

Sun, D. C. H. (1974). A controlled trial of antacid, propantheline and amylopectin sulfate in duodenal ulcer. American Journal of Gastroenterology, 60, 449-458.

Sun, D. C. H., and Ryan, M. L. (1970). A controlled study on the use of propantheline and amylopectin sulphate (SN263) for recurrences in duodenal ulcer. Gastroenterology, 58, 756-761.

Zimmon, D. S., Miller, G., Cox, G., and Tesler, M. A. (1969). Specific inhibition of gastric pepsin in the trestment of gastric ulcer. Gastroenterology, 56, 19-23. 